\section{Salivary Lactoferrin Levels, Disease Severity and Correlates in Patients with Chronic Periodontitis Presenting to a Tertiary Health Facility in Nigeria.}

\footnotetext{
*Vera Eigbibhalu ORHUE, **Adebola Oluyemisi EHIZELE, **Osagie AKHIONBARE, **Patrick OJEHANON

[*Department of Preventive Dentistry, University of Medical Sciences, Ondo state, Nigeria.

**Department of Periodontics, University of Benin Teaching Hospital, Edo state, Nigeria.]
}

\section{Correspondence}

Dr Vera E Orhue

Department of Preventive Dentistry, Faculty of Dental Sciences, University of Medical Sciences, Ondo State, Nigeria.

Email: eigbibhalu@gmail.com

\author{
Vera E Orhue \\ https://orcid.org/0000-0001-8747-6578 \\ Adebola O. Ehizele \\ https://orcid.org/0000-0002-9596-2020 \\ Osagie Akhionbare \\ https://orcid.org/0000-0002-1770-5010
}

\section{ABSTRACT}

Objective: This study compared the concentration of salivary lactoferrin in patients with and without chronic periodontitis and investigated correlations with clinical variables of the disease.

Methods: The study included 102 participants (51 cases and 51 controls) who presented at the Periodontology Clinic of University of Benin Teaching Hospital and met the selection criteria of ' $4 \mathrm{~mm}$ and above' periodontal probing depths (PPD) and positive bleeding on probing (BOP) using community periodontal index (CPI) probe. Healthy participants (controls) were patients that had PPD less than or equal to $3 \mathrm{~mm}$, absence of BOP and simplified oral hygiene index (OHI-S) not more than 1.2. Baseline OHI-S and CPI scores were recorded. Saliva samples were collected and analyzed using enzyme-linked immunosorbent assay. All data were analyzed with the Statistical Package for Social Sciences (SPSS) version 22.0.

Results: There was a statistically significant difference between the mean (SD) lactoferrin concentration of control participants $5.27(0.59) \mathrm{mg} / \mathrm{l}$ and case participants $6.74(0.61)$ $\mathrm{mg} / \mathrm{l}(\mathrm{p}<0.001)$. Participants with probing pocket depths (PPD) of $6 \mathrm{~mm}$ or more had a significantly higher mean concentration $[6.85(0.06) \mathrm{mg} / \mathrm{l}]$ than that of those with PPD 4-5mm [6.71(0.67) mg/l] $(p<0.001)$ Lactoferrin levels were highest in participants with 'poor' oral hygiene [6.85(0.6o) $\mathrm{mg} / \mathrm{l}$ ] and lowest in those with 'good' oral hygiene [6.65(0.83) $\mathrm{mg} / \mathrm{l}]$.

Conclusion: Salivary lactoferrin levels were higher among participants with chronic periodontitis than those without chronic periodontitis and correlates positively with the main clinical characteristics of the disease Keywords: Lactoferrin, saliva, chronic periodontitis, clinical correlates.

Received: 13 Aug, 2021

Revision: 17 Nov, 2021

Accepted: 22 Nov, 2021

Citation: Orhue VE, Ehizele AO, Akhionbare O, Ojehanon P. Salivary lactoferrin levels, disease severity and correlates in patients with chronic periodontitis presenting to a tertiary health facility in Nigeria. Nig J Dent Res 2022; 7(1):60-66 


\section{INTRODUCTION:}

Periodontitis is a chronic inflammatory disease of the periodontium caused by the interaction of microorganisms with the host immune system. ${ }^{1,2}$ The inflamed gingival sulcus contains a large amount of polymorphonuclear (PMN) leukocytes which play both a protective and destructive role in the pathogenesis of periodontal disease. ${ }^{3,4}$ When PMN leukocytes phagocytose microorganisms, they generate reactive oxygen species (ROS) during the oxidative killing/degradation of these organisms. ${ }^{2}$ Reactive oxygen species and cytokines are believed to be largely responsible for the periodontal tissue destruction that subsequently accompanies periodontal inflammation. ${ }^{2} \mathrm{~A}$ number of biomarkers such as matrix metalloproteinases (MMPs), interleukins and tumor necrosis factor - alpha, are being investigated as useful candidates for early diagnosis of chronic periodontitis. ${ }^{5,6}$ However, most of these markers detect periodontal destruction rather than the initial oxidative stress that occurs during periodontal inflammation. ${ }^{5}$

The pathogenesis of chronic periodontitis and a wide range of disorders such as arthritis, adult respiratory distress syndrome, Alzheimer's disease and Parkinson's disease are strongly linked to oxidative stress arising from the imbalance between ROS and the host antioxidant system.7,8,9. Ferric ions and sometimes copper ions catalyze formation of highlyreactive oxygen species such as hydroxyl radical. The accumulation of hydroxyl radicals results in cellular breakdown, tissue and DNA damage. ${ }^{8}$ Thus, sequestration of ferric ions is vital in the antioxidant defence. ${ }^{9}$

Antioxidant mechanisms sequestrate ROS before they inflict damage to the tissues. Hence, natural antioxidants in humans are studied to determine their usefulness as reliable biomarkers of periodontal disease. ${ }^{10}$

Lactoferrin (LF) is a host defense factor that reflects the degree of oxidative stress and thus severity of periodontal inflammation. ${ }^{11}$ It is an iron-binding glycoprotein belonging to the transferrin family and a component of a number of human secretions including saliva and gingival crevicular fluid (GCF). ${ }^{12}$ It is synthesized by exocrine glands and neutrophils in infected and inflamed sites. ${ }^{13}$ It chelates two ferric ions per molecule resulting in less concentration of free iron radicals in body fluids. ${ }^{14}$ This inhibits microbial growth and hinders the formation of ROS and related inflammatory processes. ${ }^{13}$

Polymorphonuclear (PMN) leukocytes are the only leukocytes that store LF in their secretory granules in large amounts with only trace content in serum. ${ }^{15}$ Traditionally, qualitative assessment of GCF has been helpful in determining the state of active disease, response to periodontal therapy, and the nature of the process occurring within the supporting periodontal tissues. ${ }^{16}$ However, technical concerns regarding the collection and analysis of GCF samples stimulated research trends towards analysis of saliva into which the constituents of GCF flow. ${ }^{17}$ Such technical concerns include, the extremely low volume of GCF in healthy sulci, high viscosity of the GCF, long collection period when using micropipettes and the risk of trauma due to prolonged holding time. ${ }^{2,18}$

Saliva is a readily available fluid containing locallyproduced microbial/host response mediators and systemic (serum) markers, that aid the diagnosis of chronic gingivitis and chronic periodontitis. ${ }^{19}$ Also the method of collection is less technical. Hence, there is increasing evidence supporting the use of saliva as a non-invasive tool for monitoring biomarkers in healthy and pathological conditions. ${ }^{20}$ Though saliva cannot give site-specific information like GCF, they are useful for whole mouth followup. ${ }^{19}$ Extensively researched biomarkers such as the MMPs have been found in whole stimulated saliva of patients with chronic periodontitis thus use of saliva as a diagnostic medium is not new in periodontics. ${ }^{21}$ Salivary LF is derived mainly from the salivary glands and the GCF during periodontal inflammation. It is both bacteriostatic and bacteriocidal. ${ }^{22,} 23$ Thus, LF in saliva represents an important defense factor against bacterial injuries including those related to Streptococcus mutans and periodontopathic bacteria. ${ }^{13}$ This is through its ability to decrease bacterial growth, biofilm development, iron overload, reactive oxygen formation and inflammatory processes. Similar qualities of LF in pancreatic fluid have led to the establishment of faecal LF as a sensitive marker of inflammatory bowel disease as well as predictor of impending clinical relapse. ${ }^{24-27}$ In the GCF, significantly higher levels of lactoferrin have been found in periodontal pocket areas compared to healthy gingival sulcus. ${ }^{28}$ A raised GCF lactoferrin level in periodontitis is thus 
expected to reflect in the salivary lactoferrin concentration in an appropriate manner when inflammatory salivary gland diseases are excluded.

This study compared the concentration of salivary lactoferrin in patients with chronic periodontitis and without chronic periodontitis and their clinical correlations.

\section{METHODOLOGY:}

This cross-sectional study was conducted in the Periodontology Clinic of the University of Benin Teaching Hospital (UBTH), Benin City, Edo State, Nigeria. The protocol for human participation was approved by the Ethics and Research Committee of the UBTH. Participants who met the selection criteria were recruited after obtaining informed consent. Demographic details such as gender, age, highest level of education and occupation were recorded, as well as information on previous dental treatment. Case participants were selected as those who met the selection criteria of ' $4 \mathrm{~mm}$ and above' periodontal probing depths (PPD) and positive bleeding on probing (BOP) using community periodontal index (CPI) epidemiological probe. Healthy participants (control) were selected from patients with PPD less than or equal to $3 \mathrm{~mm}$, absence of BOP and good simplified oral hygiene index (OHI-S).4, 29 Strict exclusion criteria were followed discarding patients less than 18 years of age, those that had more than two PPD sites per dentition, pregnant or lactating women, menopausal and postmenopausal women, those with history of smoking, those with acute infections like acute apical periodontitis, rhinitis, typhoid fever within the last two months. Baseline recording of clinical parameters was done using $\mathrm{OHI}$ $\mathrm{S}$ and $\mathrm{CPI}$-modified. ${ }^{29,}{ }^{30}$

The participants thereafter rinsed their mouths with water for 30 seconds, spat out and waited for 10 minutes before chewing on paraffin wax. This was to limit the incidence of saliva contamination with blood. The paraffin wax was chewed at a constant rate of one chew per second and saliva collected every 15 seconds by spitting into a vial until a minimum of 2 milliliters of saliva sample was obtained. ${ }^{31}$ Chewing was alternated between each side of the dentition every 15 seconds for 1 minute.

The stimulated saliva samples were transported in an ice pack medium to the UBTH chemical pathology laboratory, where it was stored in an ultra-freezer at $-80^{\circ} \mathrm{C}$ to avoid repeated freeze-thaw cycles. It took five weeks to collect the samples from all participants. After the collection period, saliva samples were thawed and analyzed in the laboratory using Enzyme-Linked Immunosorbent Assay (ELIZA). All data were analyzed using the Statistical Package for Social Sciences (SPSS) version 22.0 for frequency distributions, cross-tabulation, means and standard deviation. Independent sample t-tests were used to determine the statistical significance pattern between the salivary lactoferrin concentration of participants with and without chronic periodontitis. One-way analysis of variance (ANOVA) was applied to compare LF at the different levels of $\mathrm{OH}$ status. $\mathrm{P}$ values less than 0.05 were considered statistically significant.

RESULTS:

A total of 102 participants ( 51 cases and 51 control participants) who met the selection criteria were recruited for the study.

Majority of the control participants (54.9\%) were less than 41 years of age while the majority of case participants (53.0\%) were 41 years and above. Professionals and students (94.1\%) constituted the majority in the control group while the case group was more of professionals and traders/craftsmen (68.6\%). There was a slight female predominance (M: $F, 1: 1.1$ and 1:1.2) in both the control and case group respectively.

More than half of the participants [27 (52.9\%)] with periodontal disease had fair oral hygiene All participants bled on probing. All participants had periodontal pockets with $41(80.4 \%)$ of them recording 4-5mm depth. [Table 2]

There was a statistically significant difference between the mean lactoferrin concentration of control participants and case participants $(p<0.001)$. The case participants had a higher mean (SD) of $6.74(0.61) \mathrm{mg} / \mathrm{l}$ compared to participants in the control group 5.27(0.59) mg/l.[Table 3]

The difference in the mean lactoferrin concentration of both PPD groups was statistically significant $(p<0.001)$, participants with probing depths of $6 \mathrm{~mm}$ or more had a higher mean (SD) concentration of $6.85(0.06) \mathrm{mg} / \mathrm{l}$ compared to those with PPD of $4^{-}$ $5 \mathrm{~mm}[6.71(0.67) \mathrm{mg} / \mathrm{l}]$. [Table 4]. Lactoferrin levels were highest in those with poor oral hygiene and lowest in those with good category. However, 
statistical analysis showed no significance. $(p=$ 0.414). [Table 5].

Table 1: Participants Demographics

\begin{tabular}{|c|c|c|c|}
\hline & $\begin{array}{r}\text { Control } \\
\mathrm{n}(\%) \\
\end{array}$ & $\begin{array}{r}\text { Cases } \\
\mathrm{n}(\%) \\
\end{array}$ & $\begin{array}{l}\text { Total } \\
\mathrm{n}(\%)\end{array}$ \\
\hline \multicolumn{4}{|l|}{ Age } \\
\hline$<30$ & $13(25 \cdot 5)$ & $8(15 \cdot 7)$ & $21(20.6)$ \\
\hline $31-40$ & $15(29 \cdot 4)$ & $16(31.4)$ & $31(30.4)$ \\
\hline $41-50$ & $12(23.5)$ & $8(15 \cdot 7)$ & $20(19.6)$ \\
\hline $51-60$ & $6(11.8)$ & $9(17.7)$ & $15(14 \cdot 7)$ \\
\hline $61-70$ & $5(9.8)$ & $10(19.6)$ & $15(14.7)$ \\
\hline \multicolumn{4}{|l|}{ Sex } \\
\hline Male & $24(47.1)$ & $23(45.1)$ & $47(46.1)$ \\
\hline Female & $27(52.9)$ & $28(54.9)$ & $55(53.9)$ \\
\hline \multicolumn{4}{|l|}{ Occupation } \\
\hline Professional & $27(52.9)$ & $28(54.9)$ & $55(53.9)$ \\
\hline Students & $21(41.2)$ & $7(13.7)$ & $28(27 \cdot 5)$ \\
\hline Traders/Craftsmen & $1(1.9)$ & $10(19.6)$ & $11(10.8)$ \\
\hline Retired/Unemployed & $2(3.9)$ & $6(11.8)$ & $8(7.8)$ \\
\hline \multicolumn{4}{|l|}{ Educational Status } \\
\hline Tertiary & $47(92.2)$ & $35(68.6)$ & $82(80.4)$ \\
\hline Secondary & $4(7.8)$ & $10(19.6)$ & $14(13 \cdot 7)$ \\
\hline Primary & $0(0.0)$ & $4(7.8)$ & $4(3.9)$ \\
\hline Informal & $0(0.0)$ & 2(3.9) & $2(2.0)$ \\
\hline Total & $51(100.0)$ & $51(100.0)$ & $102(100.0)$ \\
\hline
\end{tabular}

Table 2: Clinical parameters of participants with periodontitis (case group)

\begin{tabular}{ll}
\hline Clinical parameters & $\mathrm{n}(\%)$ \\
\hline Oral Hygiene Status & $14(27.5)$ \\
Good & $27(52.9)$ \\
Fair & $10(19.6)$ \\
Poor & \\
Bleeding on Probing & $0(0.0)$ \\
Absence of Bleeding & $51(100.0)$ \\
Presence of Bleeding & \\
Probing pocket Depth & $41(80.4)$ \\
Probing depth 4 $-5 \mathrm{~mm}$ & $10(19.6)$ \\
Probing depth 6mm or more & $51(100.0)$ \\
Total &
\end{tabular}

Table 3: Comparison of mean salivary lactoferrin concentrations between control participants and case participants.

\begin{tabular}{llccccc}
\hline & & $\mathbf{n}$ & Mean & SEM & t & P value \\
\hline $\begin{array}{l}\text { Lactoferrin Concentration } \\
(\mathrm{mg} / \mathrm{l})\end{array}$ & Control & 51 & 5.27 & 0.59 & -11.99 & $<0.001^{*}$ \\
& & & & & & \\
& Case & 51 & 6.74 & 0.61 & & \\
\hline
\end{tabular}


Table 4: Comparison of mean salivary lactoferrin concentrations between case participants by pocket depth.

\begin{tabular}{lllll}
\hline & $\mathbf{n}$ & Mean \pm SD & t & p-value \\
\hline Probing depth 4-5 mm & 41 & $6.71 \pm 0.67$ & -4.32 & $<0.001$ \\
Probing depth 6 mm or more & 10 & $6.85 \pm 0.06$ & & \\
\hline
\end{tabular}

Table 5: Relationship between the mean lactoferrin concentrations and OHI-S

\begin{tabular}{lllll}
\hline & & $\mathrm{n}$ & Mean \pm SD & p-value \\
\hline OHI-S & Good & 14 & $6.65 \pm 0.83$ & 0.414 \\
& Fair & 27 & $6.84 \pm 0.04$ & \\
& Poor & 10 & $6.85 \pm 0.60$ &
\end{tabular}

p-value was calculated by one-way analysis of variance

\section{DISCUSSION}

This study was conducted among adults above 18 years of age. It comprised of two groups namely the case group $(51$ participants with chronic periodontitis) and the control group (51 participants without chronic periodontitis). Majority of the participants in the control group were less than 41years of age while majority of the participants in the case group were 41years and above. This finding correlates with previous studies that affirmed that chronic periodontitis is prevalent in those above 40 years of age. ${ }^{32,33}$

A slight female preponderance was observed in this study for both control (52.9\%) and case participants (54.9\%). This corroborates previous studies which reported higher utilization of dental care services by females. ${ }^{34}, 35,36,37$ Females have been reported to be more conscious about their health and to have a more positive attitude towards their dental health. ${ }^{38,}$ 39

Most of the participants (80.4\%) in this study had tertiary level of education and $53.9 \%$ were professionals. This could be attributed to the study center being located in a university community. Majority of the case participants (52.9\%) had fair oral hygiene $(\mathrm{OH}), 27.5 \%$ had good $\mathrm{OH}$ and $19.6 \%$ poor $\mathrm{OH}$. However, the result was in slight contrast with the study by Ehizele and Akhionbare $4^{0}$ where majority of case participants had good $\mathrm{OH}$. This may be because their study involved young adults (age 20- 40years). A study reported that $\mathrm{OH}$ standards decrease with age stating factors such as increasing worries of life, decreasing salivary flow and decline in dexterity as reasons ${ }^{41}$.

Majority of the case participants (80.4\%) had probing depths of ' 4 to $5 \mathrm{~mm}$ ' compared with $19.6 \%$ who had ' $6 \mathrm{~mm}$ and above'. This was similar to $82.4 \%$ recorded for cases of ' 4 to $5 \mathrm{~mm}^{\prime}$ in another Nigerian study..$^{40}$ The average salivary LF concentration of $5.72 \mathrm{mg} / \mathrm{l}$ for the control participants in this study was within the normal range for stimulated saliva which is $4.7 \mathrm{mg} / \mathrm{l}$ to $8 \mathrm{mg} / \mathrm{l}{ }^{10,}{ }^{11}$ The average concentration for the case participants, was significantly higher than that of the control participants. Similar result was obtained by Glimvall et al ${ }^{42}$ signifying that chronic periodontitis caused an elevation of the salivary lactoferrin concentration. Yadav et $\mathrm{al}^{9}$ and Tsai et al ${ }^{43}$ recorded similar result with GCF samples. This increase of LF concentration in chronic periodontitis patients is due to the influx of PMN leucocytes to the periodontal pocket with subsequent release of LF by the neutrophils during the oxidative killing of pathogens. In this way, more LF is released into the GCF and saliva. Salivary lactoferrin will therefore be useful in detecting active chronic periodontitis especially those that may be missed during routine clinical examination. It will also help to monitor disease progression.

Clinical parameters used in this study correlated positively with lactoferrin levels. The higher measurements of the parameters corresponded to higher LF levels in saliva. Increasing salivary LF concentrations were observed from good to poor $\mathrm{OH}$ status, however the relationship was not significant. 
Also, average lactoferrin concentration of case participants with ' $6 \mathrm{~mm}$ and above' probing pocket depth was higher than those with ' $4-5 \mathrm{~mm}^{\prime}$ depth. This relationship was significant and corroborates findings reported by Yadav et al for GCF9.

\section{CONCLUSION}

Salivary lactoferrin levels among participants with chronic periodontitis were higher than that among the healthy participants and the levels correlate positively with periodontal probing depths and $\mathrm{OH}$ status of the participants. Assessment of salivary lactoferrin levels can be adopted as a simple, noninvasive method for early detection of chronic periodontitis and can be combined with other sensitive biomarkers for formulation of highaccuracy chairside diagnostic kits and possibly kits for home use.

\section{SOURCE OF SUPPORT}

Nil

\section{CONFLICT OF INTEREST}

None declared

\section{REFERENCES}

1. Newman MG, Takei HH, Klokkevold PR, Carranza FA. Carranza's Clinical Periodontology $13^{\text {th }}$ ed. Saunders Elsevier 2018; p.240-242,479481, 695-698.

2. Bathla S, Bathla M. Periodontics Revisited. $1^{\text {st }}$ ed. Jaypee Brothers 2011; p. 84-86; 186-188; 125 127; 265-266.

3. Jentsch $H$, Sievert $Y$, Gocke R. Lactoferrin and other markers from gingival crevicular fluid and saliva before and after periodontal treatment. J Clin Periodontol 2004; 3:511-514.

4. Eley BM, Soory M, Manson JD. Periodontics $6^{\text {th }}$ Edition. Elsevier Limited 2010; p. 28, 142-145, 220-221.

5. Zhang $Y$, Kang $N$, Xue $F$, et al. Evaluation of salivary biomarkers for the diagnosis of periodontitis. BMC Oral Health 2021; 21: 266.

6. Cafiero C, Spagnuolo G, Marenzi G, et al. Predictive periodontitis: the most promising salivary biomarkers for early diagnosis of periodontitis. J. Clin. Med. 2021; 10: 1488.

7. Chapple IL. Reactive oxygen species and antioxidants in inflammatory diseases. J Clin Periodontol 1997; 24:287-296.

8. Dental Antioxidants Foundation. Salivary antioxidants. c2010. [Cited 2021 Oct 2021].
Available on www.dentalantioxidants.com/ salivary-antioxidants.

9. Halliwell B. Reactive oxygen species in living systems: source, biochemistry, and role in human disease. Am J Med 1991; 9:14S-22S.

10. Page RC. Host response tests for diagnosing periodontal diseases. J Periodontol. 1992; 63:356-366.

11. Yadav N, Lamba AK, Thakur A, Faraz, Tandon $S$,Pahwa. Effect of periodontal therapy on lactoferrin levels in gingival crevicular fluid. Aust Dent Ass 2014; 59: 314-320.

12. Tenovuo J. Human Saliva: clinical chemistry and microbiology. CRC press, 1989. 1:pp111

13. Valenti $P$, Antonini G. Lactoferrin: an important host defence against microbial and viral attack. Cell Mol Life Sci. 2005; 62:2576-2587.

14. Berlutti F, Pantanella F, Natalizi T, et al. Antiviral properties of lactoferrin-a natural immunity molecule. Molecules 2011; 16:6992-7018.

15. Kivadasannavar AV, Pudakalakatti PS, Hattarki SA, Kambali SS. Estimation of lactoferrin levels in gingival crevicular fluid before and after periodontal therapy in patients with chronic periodontitis. Contemp Clin Dent 2014; 5: 25-30.

16. Lonnerdal B, lyer S. Lactoferrin: molecular structure and biological function. Annu Rev Nutr. 1995; 15:93-110.

17. Tözüm TF, Hatipog lu H, Yamalik N, et al. Critical steps in electronic volume quantification of gingival crevicular fluid: the potential impact of evaporation, fluid retention, local conditions and repeated measurements. J Periodontal Res. 2004; 39:344-357.

18. Sachio T, Mamoru S, Masaki T, Fumio N. Current status of proteomic technologies for discovering and identifying gingival crevicular fluid biomarkers for periodontal disease. Int. J. Mol. Sci. 2019; 20:86.

19. Kaufman E, Lamster IB. Analysis of saliva for periodontal diagnosis. J Clin Periodontol 2000; 27: 453-465.

20. Papacosta E, Nassis GP. Saliva as a tool for monitoring steroid, peptide and immune markers in sport and exercise science. J Sci Med Sport. 2011; 14:424-434.

21. Ingman T, Tervahartiala T, Ding $Y$, et al. Matrix metalloproteinases and their inhibitors in gingival crevicular fluid and saliva of 
periodontitis patients. J Clin Periodontol 1996; 23: 1127-1132.

22. Friedman SA, Mandel ID, Herrera MS. Lysozyme and lactoferrin quantitation in the crevicular fluid. J Periodontol 1983; 54:347-350.

23. Kalmar J, Arnold R. Killing of Actinobacillus actinomycetemcomitans by human lactoferrin. Infection and Immunity 1988; 56: 2552-2557.

24. Walker TR, Land ML, Kartashov A et al. Fecal lactoferrin is a sensitive and specific marker of disease activity in children and young adults with inflammatory bowel disease. J Pediatr Gastroenterol Nutr 2007; 44:414-422.

25. Sidhu $R$, Wilson $P$, Wright $A$ et al. Faecal lactoferrin-a novel test to differentiate between the irritable and inflamed bowel? Aliment Pharmacol Ther 2010; 31:1365-1370.

26. Jones J, Loftus EV Jr, Panaccione $\mathrm{R}$ et al. Relationships between disease activity and serum and fecal biomarkers in patients with Crohn's disease. Clin Gastroenterol Hepatol 2008; 6:1218-1224.

27. Gisbert JP, Bermejo F, Perez-Calle JL et al. Fecal calprotectin and lactoferrin for the prediction of inflammatory bowel disease relapse. Inflamm Bowel Dis 2009; 15:1190-1198.

28. Adonogianaki E, Moughal NA, Kinane DF. Lactoferrin in the gingival crevice as a marker of polymorphonuclear leucocytes in periodontal diseases. J Clin Periodontol 1993; 20:26-31.

29. Marya CM. A Text Book of Public Health dentistry. $1^{\text {st }}$ ed. Jaypee Brothers 2011, p. 187202.

30. Oral Health Surveys: Basic methods. $5^{\text {th }}$ ed. WHO Press 2013; p. 47-50.

31. Jalil RA, Ashley FP, Wilson RF, Wagaiyu EG. Concentrations of thiocyanate, hypothiocyanite, 'free' and 'total' lysozyme, lactoferrin and secretory $\lg A$ in resting and stimulated whole saliva of children aged 12-14 years and the relationship with plaque accumulation and gingivitis. J Periodontal Res. 1993; 28:130-136.

32. Umoh AO, Azodo CC. Prevalence of gingivitis and periodontitis in an adult male population in Nigeria. Niger J Basic Clin Sci 2012; 9:65-69
33. Heitz-Mayfield LJA, Schatzle M, Loe $H$, et al. Clinical course of chronic periodontitis. II. Incidence, characteristics and time of occurrence of the initial periodontal lesion. J Clin Periodontol. 2003; 30:902-908.

34. Okunseri C, Born D, Chattopadhyay A. Self reported dental visits among adults in Benin City, Nigeria. Int Dent J. 2004; 54:127-130

35. Ansari JM, Honkala S. Gender differences in oral health Knowledge and behavior of the health science college students in Kuwait. J Allied Health. 2007; 36:41-46

36. Oyapero A, Owoturo E.O. Factors associated with knowledge and attitude to the use of dental floss at some private and public dental clinics in Lagos State. Edorium J. Dent. 2016; 3:12-20.

37. Akaji E.A, Chukwuneke F.N, Okeke U.F. Attendance pattern amogst patients at the Dental clinic of the University of Nigeria Teaching Hospital, Enugu, Nigeria. Niger J. Med. 2012; 21: 74-77.

38. Ostberg $A L$, Halling $A$, Lindblad $U$. Gender differences in knowledge, attitude, behavior and perceived oral health among adolescents. Acta Odontol Scand. 1999; 57:231-236.

39. Fukai K, Takaesu Y, Maki Y. Gender differences in oral health 16 . Behavior and general health habits in an adult population. Bull of Tokyo Dent Coll 1999, 40:187-193.

40. Ehizele A, Akhionbare O. Effect of non-surgical periodontal therapy on the concentration of volatile sulphur compound in mouth air of a group of Nigerian young adults. Ann Med Health Sci Res. 2013; 3: 433-437.

41. Krustrup U, Erik Peterson P. Periodontal conditions in 35-44- and 65-74-year-old adults in Denmark. Acta Odontol Scand. 2006; 64-65-73.

42. Glimvall $P$, Wickstrom $C$, Jansson $H$. Elevated levels of salivary lactoferin, a marker for chronic periodontitis? J Periodont Res 2012; 47:665-66o.

43. Tsai CC, Kao CC, Chen CC. Gingival crevicular fluid lactoferin levels in adult periodontitis patients. Aust Dent J. 1998; 43:40-44. 